\title{
Femoroacetabular Impingement
}

\author{
Paul Magill*, Joseph F. Baker and Kevin J. Mulhall
}

Sports Surgery Clinic, Santry Demesne, Dublin 9, Ireland

\begin{abstract}
Hip and groin pain has, for many years, been a difficult diagnostic challenge. In the past decade there has been increased focus on femoroacetabular impingement (FAI) as a cause. FAI is now considered by many as a primary cause of hip joint degeneration. Our appreciation and understanding of FAI is currently increasing at an exponential rate. In this paper we review FAI as a pathology and review the current practice for diagnosis and treatment.
\end{abstract}

Keywords: Hip, impingement, cam, pincer, arthroscopy.

\section{WHAT IS FEMOROACETABULAR IMPINGEMENT?}

Femoroacetabular impingement (FAI), although considered a relatively new syndrome, has origins dating back further than most appreciate [1]. Interest in the topic faded until Ganz became interested in the 1990's [1, 2]. Since this time the number of scientific publications on the subject has increased exponentially [3]. It has come back into vogue as a number of authors have recently began to shed light on the associated pathomechanics [4]. The diagnosis is made based on clinical history and exam findings with additional support gained from plain film radiography and/or MRI. It is easiest to understand the concept when considering the hip joint consists of femoral and acetabular components.

It is accepted at present that there are two types of lesion that may cause FAI. On the femoral side one may encounter a Cam lesion. This is an abnormal contour on the anterosuperior aspect of the femoral head-neck junction resulting in the loss of the normal spherical contour of the femoral head $[5,6]$. This derives from the true meaning of cam, which may mean a mound of earth or refer to a projection from mechanical piece to alter movement against another. This creates an increased working diameter of the femoral head at certain points of articulation within the acetabulum. During flexion of the joint the eccentric portion of the head induces shear stresses and compression of the cartilage. The labrum is stretched and pushed outwards while the cartilage is driven inwards - this results in an undersurface tear of the labrum (Fig. 1) [7]. In effect the femoral head is too large for the acetabulum at certain points of the articulation [7].

On the acetabular side a Pincer lesion may be seen. This refers to over coverage of the femoral head by the acetabulum and subsequently the range of movement available before the femoral neck abuts the outer margins of the acetabulum. In effect the acetabulum is too deep for the femoral head [7]. The labrum can be compressed between the femoral neck and underlying subchondral bone.

*Address correspondence to this author at the Sports Surgery Clinic, Santry Demesne, Dublin 9, Ireland; Tel: +353-1-5262247; Fax: +353-1-5262249; E-mail: pmagill8@hotmail.com
The resulting cartilage abnormalities are reflective of the different mechanics of each type of lesion. Cam lesions tend to produce diffuse cartilage lesions due to a greater area of impingement. Pincer lesions lead to more focal areas of cartilage loss [8]. The acetabular labrum is predisposed to damage via repetitive microtrauma and shear forces at the sites of impingement [8]. Pincer type impingement has a more pronounced effect on the labrum than a Cam lesion, and chronic impaction may result in calcification or ossification of the labrum perpetuating the whole impingement process [8].

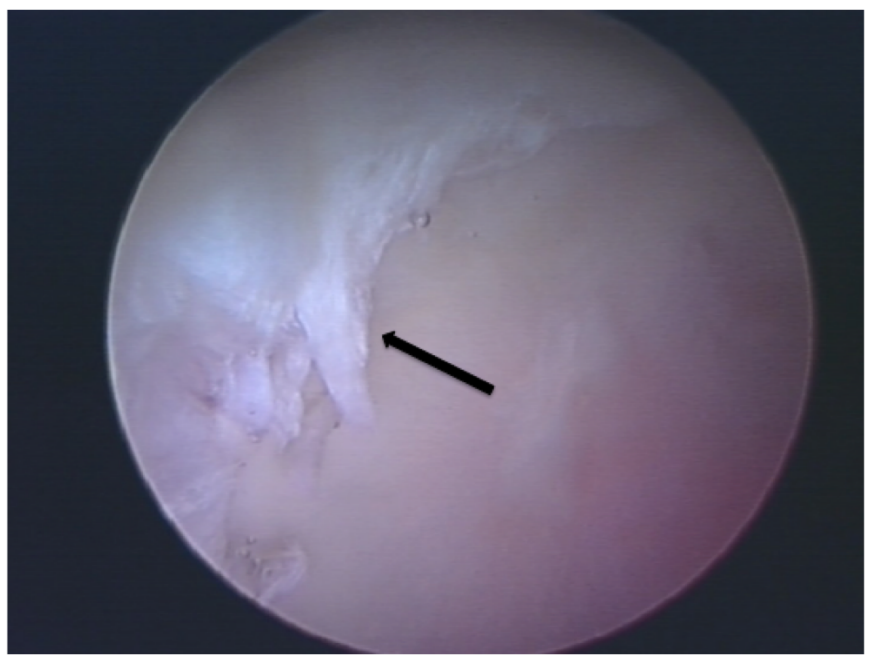

Fig. (1). Extensive undersurface tear of the acetabular labrum as indicated by arrow.

Degenerative arthritis is the feared end stage state of the impingement process. This results from the recurrent shear forces across the articular cartilage and damage to this and the subchondral bone $[2,9]$. The role that a Cam lesion plays in this development is supported by the finding that up to $40 \%$ of patients with osteoarthritis of the hip have radiological features consistent with a Cam lesion [10]. Due to the potential development of degenerative joint disease, early identification is necessary as there is some indication that early intervention may serve to delay progression [11]. While an abnormality on one side of the joint may be responsible for the impingement, it is possible for both sides to contribute at the same time. 


\section{PATIENT GROUP}

Patients are typically active individuals aged 25 to 50 years [11]. However, the two different patterns of FAI are accepted to generally affect different groups within this. Cam impingement typically affects young males while the Pincer mechanism is considered more common amongst older females [12]. Sporting activities that involve a repetitive axial load through the hip or frequent pivoting movements resulting in torsional forces are implicated in the cause of FAI lesions although the exact mechanism by which this happens is unclear. Soccer and ice hockey have been associated with an increased incidence of FAI.

\section{PRESENTING COMPLAINTS AND HISTORY}

Most patients do not recall a specific trauma or incident that precipitated their hip complaint. The predominant feature of FAI is pain, although patient may indicate a history of clicking, grinding or sensation of the hip joint subluxing. The pain is most often felt in the groin as with most pathologies arising from the hip joint. However, pain may also be located to the knee, lower back, over the greater trochanter or buttock $[6,13]$. Some individuals may locate the pain using their thumb and index finger over the greater trochanter region - this has been termed the C-sign (Fig. 2) and is suggestive of hip joint pathology [11]. Patients with FAI present at a younger age than do their counterparts with purely degenerative disease of the hip and they may experience pain with periods of prolonged hip flexion [14].

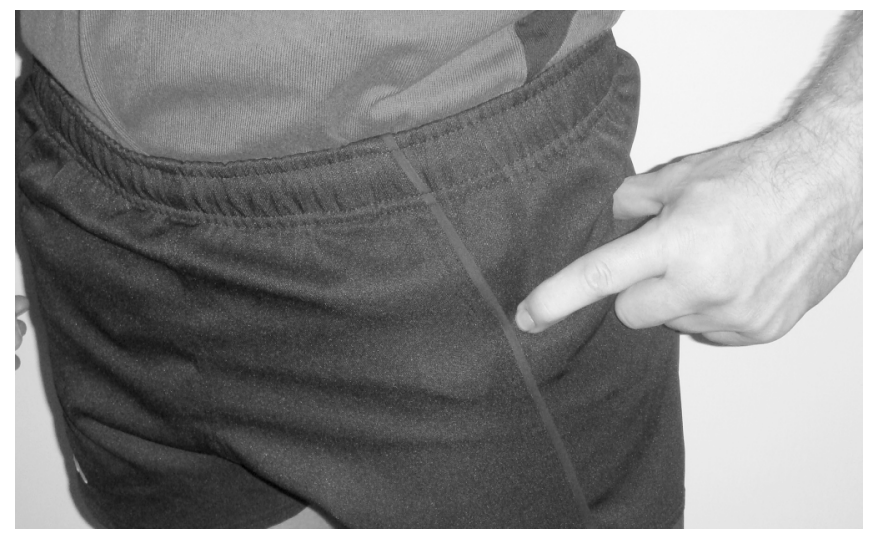

Fig. (2). Demonstration of the 'C-sign'. An attempt is made by the patient to locate the deeply felt pain with the index finger and thumb.

Previous medical history must be reviewed for possible predisposition to Cam lesions such as previous Slipped Capital Femoral Epiphysis (SCFE), Legg-Calve-Perthes disease, proximal femoral fracture, and Avascular Necrosis (AVN) $[6,15,16]$. Past history of pelvic osteotomy or hip dysplasia may predispose to Pincer lesions [8]. A systems review may unveil symptoms suggestive of an inflammatory arthropathy or spondyloarthropathy and is an essential part of the work-up.

\section{EXAMINATION FINDINGS}

Assessment of gait may reveal a Trendelenberg pattern due to weakened abductors of the affected side. Classically there is a reduced range of flexion of the affected hip and this has been shown in large cohorts of patients with confirmed FAI $[17,18]$. Others maintain however, that loss of internal rotation, out of proportion to the reduction of other movements is more supportive of the diagnosis of FAI over arthritis [8]. The classical impingement test consists of passive flexion of the hip to 90 degrees, slightly adduction of the hip then applying an internal rotation force - this should mimic the symptoms the patient experiences by producing a shear or compressive force across the acetabular labrum and associated pain [8].

A posterior impingement test can also be performed. With the patient prone the hip is passively extended and externally rotated and again this is positive if symptoms are reproduced. Alternatively with the patient supine the hip can be passively flexed, externally rotated and abducted. The distance that the knee remains off the examination couch is compared to the unaffected side. The knee of the affected side being a greater distance from the couch surface indicates posterior impingement.

\section{INVESTIGATIONS: THE ROLE OF PLAIN X-RAYS}

The anteroposterior $\mathrm{x}$-ray of the pelvis may unearth a number of signs suggestive of FAI. The "pistol grip deformity" refers to a flattening of the femoral head-neck junction indicative of a Cam lesion (Fig. 3) [8]. This may simply be considered a "bump" present at the head-neck junction although is best seen on the lateral view of the hip [19]. A femoral neck protuberance if often seen in those with long-term follow-up after Legg-Calve-Perthes disease or moderate-to-severe SCFE [20, 21]. Previous trauma may leave radiographic evidence and residual post-traumatic retroversion of the femoral head has previously identified to cause anterior impingement [22].

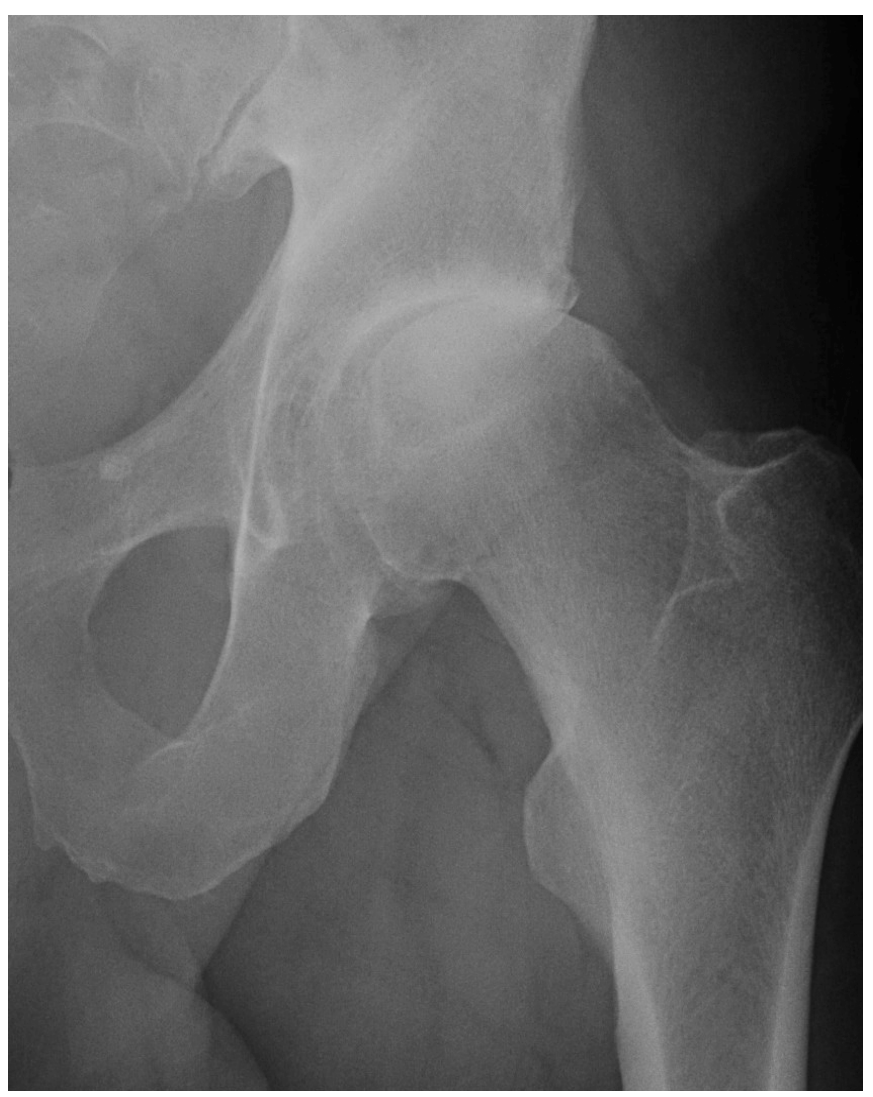

Fig. (3). Pistol grip deformity seen on an anteroposterior x-ray of the left hip with signs of established osteoarthritis. 
At the edge of the acetabulum a double line may be noticeable due to labral calcification [23]. One may look for presence of the cross over sign or ischial sign suggestive of acetabular retroversion and thus pincer lesion [24-27]. The cross-over sign refers to the anterior acetabular rim (see Fig. 4) being projected lateral to the corresponding aspect of the posterior rim [19]. Prominence of the ischial spine into the pelvis has been positively correlated with the presence of the cross-over sign and this may suggest that the retroversion is occurring in the inferior hemipelvis rather than simply at the acetabular level [26]. Coxa profunda is present if the medial wall of the acetabulum is visible on or medial to the ilioischial line [7]. If the medial edge of the femoral head extends beyond the ilioischial line then coxa protrusio is considered present [7]. It has been pointed out that all these signs are sensitive to the projection of the $\mathrm{x}$-ray beam relative to the patient and the deformity [28].

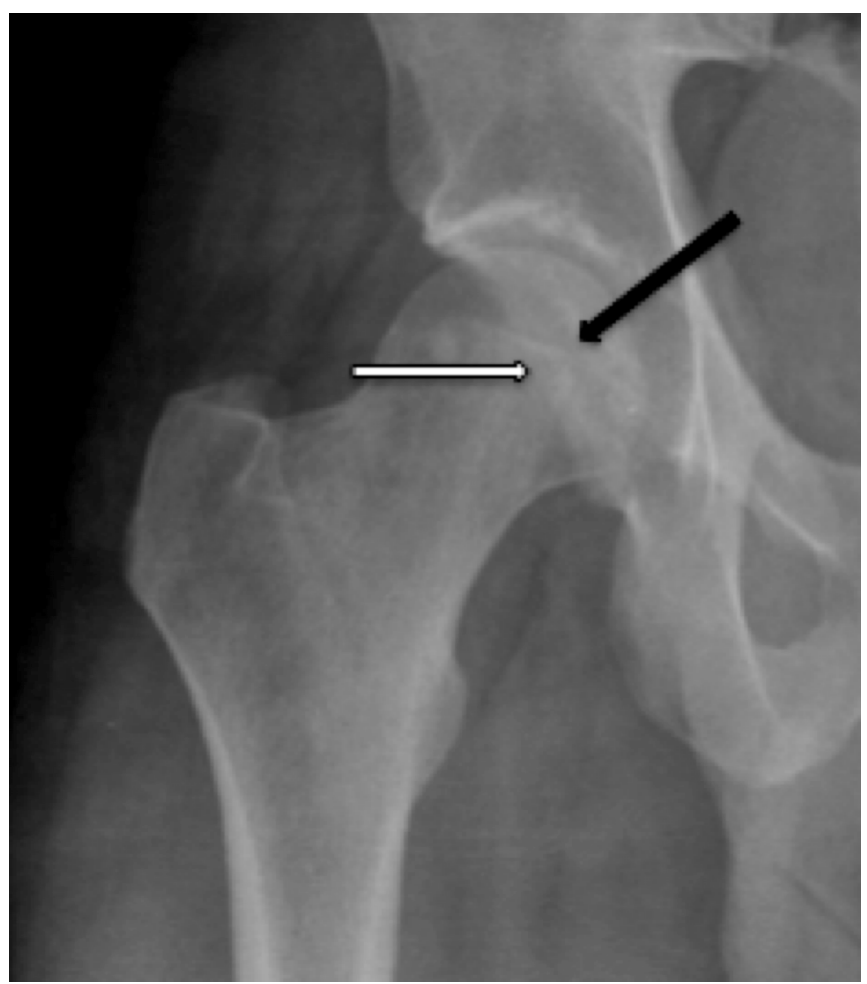

Fig. (4). A normal appearing projection of the hip. The anterior acetabular rim (solid black arrow) is projected medial to the posterior rim (white). When the anterior rim lies lateral to the posterior rim a cross is formed and is suggestive of acetabular retroversion.

Synovial herniation pits have been described previously in association with FAI. These are frequently located in the anterosuperior portion of the femoral neck. They are seen on plain films as areas of decreased bone density with illdefined borders [8]. Some are of the opinion that when these occur in this location that they may be indicative of FAI [12].

On the lateral radiograph decreased femoral head offset can be detected [8]. With the leg in 15 degrees of internal rotation the alpha-angle may be calculated [15]. It may also be calculated using the Dunn view with the hip in 90 degrees of flexion, 20 degrees of abduction and neutral rotation [29]. To calculate the alpha angle a circle of best fit is placed over the femoral head. From the first point on the head-neck junction outside the circle a line is drawn to the centre of the circle. A further line is drawn from the centre of the circle to the middle of the femoral neck. The angle between these two lines is measured $[5,15]$. The upper limit of the alpha angle has been defined at 50 degrees $[5,15]$. Beyond this the Cam lesion is considered likely to contribute to impingement.

While plain films are useful, it needs to be accepted that films not taken at the correct projection may underestimate the alpha-angle and other advanced imaging modalities may be more accurate [6].

\section{INVESTIGATIONS: THE ROLE OF MRI AND CT}

MRI demonstrates FAI well and can be considered the investigation of choice. Additionally, acetabular labral and articular cartilage damage that often accompanies FAI is also well seen. Increased signal on T2-weighted images extending to the articular surface is indicative of acetabular labral damage [8]. This signal is well defined in linear tears and less so in degenerate tears. MR arthrography is preferred to plain MR as it allows better visualization of labral pathology.

A triad of MRI findings in FAI has been described by Kassarjian et al. consisting of lost femoral head-neck junction offset, anterosuperior labral tears and adjacent chondrosis [30]. The alpha-angle may also be calculated to quantify cam type impingement on MRI [6]. An oblique axial view of the hip is best used to calculate the alpha-angle.

CT scans of the hip are less helpful although axial slices are useful for assessing acetabular version [31]. The superior portion of the acetabulum should be assessed as measuring version through the mid-portion can lead to false negative findings [32].

\section{TREATMENT OF FAI}

One of the first to report a series of 11 patients treated for FAI was Smith-Peterson. He recognized this was a mechanical problem and advocated a 'plastic procedure' to alleviate pain [33]. He performed all of his procedures on the acetabular side but recognized occasions when the femoral neck may also need attention. Although achieving good short to medium term results, he and subsequent authors of the same generation warned that they did not know the long term sequel of these plastic procedures.

We still do not know if corrective procedures significantly alter the progression of hip arthritis. However, there is sufficient evidence to show that untreated FAI leads to early osteoarthritis $[7,12,34]$. Conservative measures are therefore not widely advocated. Anti-inflammatories and activity modification may provide short term relief but do not address the underlying problem. Surgical options must therefore be employed. These include open, arthroscopic and combined techniques.

\section{OPEN SURGERY}

A significant progression in treatment was in 2001 when Ganz published excellent results on a method of open dislocation of the hip without risking the femoral head blood supply [35]. The technique involves a modified posterior approach with a trochanteric flip osteotomy to protect the 
medial circumflex artery. The femoral head is subsequently dislocated anteriorly. Because it allows direct visualization of the pathology, excision can be effective and efficient. In 2004 Beck et al. published results of the procedure on 19 FAI patients with an average follow-up of 4.7 years and found a good to excellent Merle d'Aubigne score in 13 out of the 19 hips [36]. The hips which did poorly had a degree of degeneration and as such he did not advocate this procedure in patients with greater than Grade 1 osteoarthritis. A more recent series of 48 patients by Graves et al. found $96 \%$ of his patients experienced an average improvement in Merle d'Aubigne hip score from 13 to 16.8 at 3.2 years follow-up [37]. He too advocated this procedure only in those without significant degenerative disease.

Surgical dislocation of the hip appears to be a safe procedure. To date there have been no reported cases of avascular necrosis of the femoral head and union of the trochanteric osteotomy is universally good. There is no increased incidence of post-operative arthritis, although follow-up is too short to definitively conclude this. Intraarticular adhesion formation has been reported as the most significant complication. It has been suggested that this occurs in all operated hips but only $6 \%$ of patients are symptomatic [38]. Treatment for this can be open or arthroscopic adhesiolysis but prophylaxis is obviously better and post-operative continuous, passive movement protocols are used by some surgeons [39].

Overall, open dislocation for FAI is considered a positive technique. Its major limitation is that it is only suitable for non-degenerative joints. Patient selection must be accurate and early.

Although surgical dislocation has provided the optimum exposure 'mini-open' approaches to the hip, more specifically for resection of Cam lesions have been used with favourable results. An open anterior approach without dislocation of the hip, as reported by Ribas et al., conferred an average rehabilitation time of 4.4 weeks and an improved Merle d'Aubign score [40]. They did however note a significant rate of damage to the femorcutaneous nerve with their technique. Similarly, Hartmann et al. report positive results from a mini-open approach anteriorly. They do not however that only the anterior and anterolateral aspect of the joint is accessible with this technique thus making preoperative planning essential [41].

\section{HIP ARTHROSCOPY}

Arthroscopy offers itself as a less invasive technique with the potential for both diagnosis and treatment. Sampsons' group pioneered the technique in 1987 and started using it to treat FAI in 2005 [42, 43]. It is still only practiced by hip surgeons and remains a very technical procedure. Despite this, there are already published series of over 1000 patients $[44,45]$.

Cam lesions are addressed via the peripheral compartment of the joint. Direct visualization and resection of the bony prominence is performed and checked by intermittent flexion and rotation of the joint. Byrd recently published results on treatment of 207 cam lesions [46]. He found an average increase of 20 points in the modified Harris Hip score with an average follow up 16 months. The results obtained are comparable to those with open dislocation. $94 \%$ of his patients had areas of grade III-IV articular wear so unlike the open dislocation, results are not dependent upon a healthy joint.

High level athletes have benefited from this less invasive mode of treatment. Phillipon et al. reported a greater than $90 \%$ return to sport among a cohort of 45 professional athletes undergoing arthroscopic debridement of FAI lesions at an average of 1.6 years post-surgery [47].

Pincer lesions are addressed via the central compartment. Ideally the labrum is detached, the underlying bony lesion resected and the labrum reattached to the remodeled acetabular rim. Arthroscopically, this is a very challenging procedure. Very often the labrum is badly damaged and there is a corresponding area of significant degeneration in the joint. As such, an argument can be made that little benefit will be bestowed by repairing and reattaching the labrum. However, preliminary results from open surgery would suggest it is better to repair the labrum where possible [48]. In addition there is sufficient biomechanical evidence that the labrum is important for stability and joint pressures [4951]. One could also look at the early days of knee surgery and draw on the lessons learned from meniscal excision surgery.

Complications arising after hip arthroscopy have been well audited and published. Neuropraxia due to excessive traction or inappropriate patient positioning are reported at a rate of about $2 \%$. Intra-abdominal fluid extravasations are reported in approximately 1\% [45]. Scuffing of the femoral head while inserting the instruments is rarely reported but likely to be a common occurrence. Like the other complications in hip arthroscopy, it is best prevented with meticulous preparation. Hip arthroscopy definitely has its role, and this continues to evolve.

\section{MIXED APPROACHES}

A combination of arthroscopic and open debridement has also been utilized for addressing FAI lesions. Lincoln et al. used a modified anterior Heuter approach supplemented with hip arthroscopy to perform osteoplasty for Cam lesions in 16 patients [52]. The mean Harris Hip Score increased an average of 12 points, and at an average of two-years followup there was no progression in Tonnis grades.

\section{SUMMARY}

Although the idea of FAI has been around for almost a century it is only in the past ten years that we have started to focus on it. Despite this, it is now well established as a cause of hip and groin pain in the active young adult. There is convincing evidence that it leads to the development of early hip arthritis. It is therefore an important pathology which is now set to remain in popular focus. FAI is diagnosed with some certainty on history and examination alone. Radiological tests, especially MR arthrography, are becoming more accurate to confirm and grade disease. The key to good prognosis is early surgical treatment. Open hip dislocation as described by Ganz is the current gold standard [35]. Hip arthroscopy offers a less invasive alternative but the indications and potential of this technique are still evolving. 


\section{REFERENCES}

[1] Ganz R, Bamert P, Hausner P, Isler B, Vrevc F. Cervico-acetabular impingement after femoral neck fracture. Unfallchirurg 1991; 94(4): 172-5.

[2] Myers SR, Eijer H, Ganz R. Anterior femoroacetabular impingement after periacetabular osteotomy. Clin Orthop Relat Res 1999; (363): 93-9.

[3] Leunig M, Beaulé P, Ganz R. The concept of femoroacetabular impingement: current status and future perspectives. Clin Orthop Relat Res 2009; 467(3): 616-22.

[4] Brand RA. Femoroacetabular impingement: current status of diagnosis and treatment: Marius Nygaard Smith-Petersen, 18861953. Clin Orthop Relat Res 2009; 467(3): 605-7.

[5] Beaulé PE, Zaragoza E, Motamedi K, Copelan N, Dorey FJ. Threedimensional computed tomography of the hip in the assessment of femoroacetabular impingement. J Orthop Res 2005; 23(6): 128692.

[6] Ito K, Minka MA 2nd, Leunig M, Werlen S, Ganz R. Femoroacetabular impingement and the cam-effect. A MRI-based quantitative anatomical study of the femoral head-neck offset. J Bone Joint Surg Br 2001; 83(2): 171-6.

[7] Beck M, Kalhor M, Leunig M, Ganz R. Hip morphology influences the pattern of damage to the acetabular cartilage: femoroacetabular impingement as a cause of early osteoarthritis of the hip. J Bone Joint Surg Br 2005; 87(7): 1012-8.

[8] Beall DP, Sweet CF, Martin HD, et al. Imaging findings of femoroacetabular impingement syndrome. Skeletal Radiol 2005; 34(11): 691-701.

[9] Tonnis D, Heinecke A. Acetabular and femoral anteversion: relationship with osteoarthritis of the hip. J Bone Joint Surg Am 1999; 81(12): 1747-70.

[10] Lavigne M, Parvizi J, Beck M, Siebenrock KA, Ganz R, Leunig M. Anterior femoroacetabular impingement: part I. Techniques of joint preserving surgery. Clin Orthop Relat Res 2004; (418): 61-6.

[11] Dooley PJ. Femoroacetabular impingement syndrome: Nonarthritic hip pain in young adults. Can Fam Physician 2008; 54(1): 42-7.

[12] Ganz R, Parvizi J, Beck M, Leunig M, Nötzli H, Siebenrock KA. Femoroacetabular impingement: a cause for osteoarthritis of the hip. Clin Orthop Relat Res 2003; (417): 112-20.

[13] Friend L, Kelly BT, Femoroacetabular impingement and labral tears in the adolescent hip: diagnosis and surgical advances. Curr Opin Pediatr 2009; 21(1): 71-6.

[14] Klaue K, Durnin CW, Ganz R. The acetabular rim syndrome. A clinical presentation of dysplasia of the hip. J Bone Joint Surg Br 1991; 73(3): 423-9.

[15] Nötzli HP, Wyss TF, Stoecklin CH, Schmid MR, Treiber K, Hodler $\mathrm{J}$. The contour of the femoral head-neck junction as a predictor for the risk of anterior impingement. J Bone Joint Surg Br 2002; 84(4): $556-60$.

[16] Siebenrock KA, Schoeniger R, Ganz R. Anterior femoro-acetabular impingement due to acetabular retroversion. Treatment with periacetabular osteotomy. J Bone Joint Surg Am 2003; 85-A(2): 278-86.

[17] Ito K, Leunig M, Ganz R. Histopathologic features of the acetabular labrum in femoroacetabular impingement. Clin Orthop Relat Res 2004; (429): 262-71.

[18] Murphy S, Tannast M, Kim YJ, Buly R, Millis MB. Debridement of the adult hip for femoroacetabular impingement: indications and preliminary clinical results. Clin Orthop Relat Res 2004; (429): 178-81.

[19] Blankenbaker DG, Tuite MJ. The painful hip: new concepts. Skeletal Radiol 2006; 35(6): 352-70.

[20] Ganz R, Leunig M, Leunig-Ganz K, Harris WH. The etiology of osteoarthritis of the hip: an integrated mechanical concept. Clin Orthop Relat Res 2008; 466(2): 264-72.

[21] Jaberi FM, Parvizi J. Hip pain in young adults: femoroacetabular impingement. J Arthroplasty 2007; 22(7 Suppl 3): 37-42.

[22] Eijer H, Myers SR, Ganz R. Anterior femoroacetabular impingement after femoral neck fractures. J Orthop Trauma 2001; 15(7): 475-81.

[23] Fadul DA, Carrino JA. Imaging of femoroacetabular impingement. J Bone Joint Surg Am 2009; 91 (Suppl 1): 138-43.

[24] Reynolds D, Lucas J, Klaue K. Retroversion of the acetabulum. A cause of hip pain. J Bone Joint Surg Br 1999; 81(2): 281-8.
[25] Jamali AA, Mladenov K, Meyer DC, et al. Anteroposterior pelvic radiographs to assess acetabular retroversion: high validity of the "cross-over-sign". J Orthop Res 2007; 25(6): 758-65.

[26] Kalberer F, Sierra RJ, Madan SS, Ganz R, Leunig M. Ischial spine projection into the pelvis : a new sign for acetabular retroversion. Clin Orthop Relat Res 2008; 466(3): 677-83.

[27] Siebenrock KA, Kalbermatten DF, Ganz R. Effect of pelvic tilt on acetabular retroversion: a study of pelves from cadavers. Clin Orthop Relat Res 2003; (407): 241-8.

[28] Allen D, Beaulé PE, Ramadan O, Doucette S. Prevalence of associated deformities and hip pain in patients with cam-type femoroacetabular impingement. J Bone Joint Surg Br 2009; 91(5): 589-94.

[29] Meyer DC, Beck M, Ellis T, Ganz R, Leunig M. Comparison of six radiographic projections to assess femoral head/neck asphericity. Clin Orthop Relat Res 2006; 445: 181-5.

[30] Kassarjian A, Yoon LS, Belzile E, Connolly SA, Millis MB, Palmer WE. Triad of MR arthrographic findings in patients with cam-type femoroacetabular impingement. Radiology 2005; 236(2): 588-92.

[31] Armfield DR, Towers JD, Robertson DD. Radiographic and MR imaging of the athletic hip. Clin Sports Med 2006; 25(2): 211-39, viii.

[32] Li PL, Ganz R. Morphologic features of congenital acetabular dysplasia: one in six is retroverted. Clin Orthop Relat Res 2003; (416): 245-53.

[33] Smith-Petersen MN. Treatment of malum coxae senilis, old slipped upper femoral epiphysis, intrapelvic protrusion of the acetabulum, and coxa plana by means of aceetabuloplasty. J Bone Joint Surg Am 1936; 18(4): 869-80.

[34] Ito K, Minka MA 2nd, Leunig M, Werlen S, Ganz R. Femoroacetabular impingement and the cam-effect: a mri-based quantitative anatomical study of the femoral head-neck offset. J Bone Joint Surg Br 2001; 83-B(2): 171-6.

[35] Ganz R, Gill TJ, Gautier E, Ganz K, Krügel N, Berlemann U. Surgical dislocation of the adult hip a technique with full access to the femoral head and acetabulum without the risk of avascular necrosis. J Bone Joint Surg Br 2001; 83(8): 1119-24.

[36] Beck M, Leunig M, Parvizi J, Boutier V, Wyss D, Ganz R. Anterior femoroacetabular impingement: part II. Midterm results of surgical treatment. Clin Orthop Relat Res 2004; (418): 67-73.

[37] Graves ML, Mast JW. Femoroacetabular impingement: do outcomes reliably improve with surgical dislocations? Clin Orthop Relat Res 2009; 467(3): 717-23.

[38] Krueger A, Leunig M, Siebenrock KA, Beck M. Hip arthroscopy after previous surgical hip dislocation for femoroacetabular impingement. Arthroscopy 2007; 23(12): 1285-9 e1.

[39] Beck M. Groin pain after open FAI surgery: the role of intraarticular adhesions. Clin Orthop Relat Res 2009; 467(3): 76974.

[40] Ribas M, Marín-Peña OR, Regenbrecht B, De La Torre B, Vilarrubias JM. Hip osteoplasty by an anterior minimally invasive approach for active patients with femoroacetabular impingement. Hip Int 2007; 17(2): 91-8.

[41] Hartmann A, Gunther KP. Arthroscopically assisted anterior decompression for femoroacetabular impingement: technique and early clinical results. Arch Orthop Trauma Surg 2009; 129(8): 1001-9.

[42] Glick JM. Hip arthroscopy by the lateral approach. Arthroscopy 1987; 3(1): 4-12.

[43] Sampson TG. Arthroscopic treatment of femoroacetabular impingement. Tech Orthop 2005; 20(1): 56-62.

[44] Clarke MT, Arora a, Villar RN. Hip arthroscopy: complications in 1054 cases. Clin Orthop Relat Res 2003; (406): 84-8.

[45] Sampson TG. Complications of hip arthroscopy. Tech Orthop 2005; 20(1): 63-6.

[46] Byrd J, Jones K. Arthroscopic femoroplasty in the management of cam-type femoroacetabular impingement. Clin Orthop Rel Res 2009; 467(3): 739-46.

[47] Philippon M, Schenker M, Briggs K, Kuppersmith D Femoroacetabular impingement in 45 professional athletes: associated pathologies and return to sport following arthroscopic decompression. Knee Surg Sports Traumatol Arthrosc 2007; 15(7): 908-14. 
[48] Espinosa N, Beck M, Rothenfluh DA, Ganz R, Leunig M. Treatment of femoro-acetabular impingement: preliminary results of labral refixation. J Bone Joint Surg Am 2006; 88(5): 925-35.

[49] Ferguson SJ, Bryant JT, Ganz R, Ito K. The acetabular labrum seal: a poroelastic finite element model. Clin Biomech (Bristol, Avon) 2000; 15(6): 463-8.

[50] Ferguson SJ, Bryant JT, Ganz R, Ito K. The influence of the acetabular labrum on hip joint cartilage consolidation: a poroelastic finite element model. J Biomech 2000; 33(8): 953-60.
[51] Ferguson SJ, Bryant JT, Ganz R, Ito K. An in vitro investigation of the acetabular labral seal in hip joint mechanics. J Biomech 2003; 36(2): 171-8

[52] Lincoln M, Johnston K, Muldoon M, Santore R. Combined arthroscopic and modified open approach for cam femoroacetabular impingement: a preliminary experience. Arthroscopy 2009; 25(4): 392-9.

(C) Magill et al.; Licensee Bentham Open.

This is an open access article licensed under the terms of the Creative Commons Attribution Non-Commercial License (http://creativecommons.org/licenses/by-nc/3.0/) which permits unrestricted, non-commercial use, distribution and reproduction in any medium, provided the work is properly cited. 